\title{
An In Vivo Pharmacological Screen Identifies Cholinergic Signaling as a Therapeutic Target in Glial-Based Nervous System Disease
}

\author{
Liqun Wang, ${ }^{1}$ Tracy L. Hagemann, ${ }^{2}{ }^{-}$Albee Messing, ${ }^{2}$ and Mel B. Feany ${ }^{1}$ \\ ${ }^{1}$ Department of Pathology, Brigham and Women's Hospital, Harvard Medical School, Boston, Massachusetts 02115, and ${ }^{2}$ Waisman Center, and \\ Department of Comparative Biosciences, School of Veterinary Medicine, University of Wisconsin-Madison, Madison, Wisconsin 53705
}

The role that glia play in neurological disease is poorly understood but increasingly acknowledged to be critical in a diverse group of disorders. Here we use a simple genetic model of Alexander disease, a progressive and severe human degenerative nervous system disease caused by a primary astroglial abnormality, to perform an in vivo screen of 1987 compounds, including many FDA-approved drugs and natural products. We identify four compounds capable of dose-dependent inhibition of nervous system toxicity. Focusing on one of these hits, glycopyrrolate, we confirm the role for muscarinic cholinergic signaling in pathogenesis using additional pharmacologic reagents and genetic approaches. We further demonstrate that muscarinic cholinergic signaling works through downstream $\mathrm{G} \alpha \mathrm{q}$ to control oxidative stress and death of neurons and glia. Importantly, we document increased muscarinic cholinergic receptor expression in Alexander disease model mice and in postmortem brain tissue from Alexander disease patients, and that blocking muscarinic receptors in Alexander disease model mice reduces oxidative stress, emphasizing the translational significance of our findings. We have therefore identified glial muscarinic signaling as a potential therapeutic target in Alexander disease, and possibly in other gliopathic disorders as well.

Key words: Alexander disease; chemical screen; cholinergic signaling; Drosophila; glia

\section{Significance Statement}

Despite the urgent need for better treatments for neurological diseases, drug development for these devastating disorders has been challenging. The effectiveness of traditional large-scale in vitro screens may be limited by the lack of the appropriate molecular, cellular, and structural environment. Using a simple Drosophila model of Alexander disease, we performed a moderate throughput chemical screen of FDA-approved drugs and natural compounds, and found that reducing muscarinic cholinergic signaling ameliorated clinical symptoms and oxidative stress in Alexander disease model flies and mice. Our work demonstrates that small animal models are valuable screening tools for therapeutic compound identification in complex human diseases and that existing drugs can be a valuable resource for drug discovery given their known pharmacological and safety profiles.

\section{Introduction}

The current drug discovery pipeline has been inefficient in the context of neurological disease. Approaches to therapeutic com-

\footnotetext{
Received Jan. 19, 2015; revised July 3, 2015; accepted July 28, 2015.

Author contributions: L.W. and M.B.F. designed research; L.W. and T.L.H. performed research; A.M. contributed unpublished reagents/analytic tools; L.W., T.L.H., A.M., and M.B.F. analyzed data; L.W. and M.B.F. wrote the paper. This work was supported by National Institutes of Health-National Institute of Neurological Disorders and Stroke Grant P01 NS042803, Intellectual and Developmental Disabilities Research Centers at Children's Hospital Boston Grant P30 HD18655, and Waisman Center Grant P30 HD03352. Fly stocks were obtained from the Bloomington Drosophila Stock Center (National Institutes of Health Grant P40 0D018537), TRiP at Harvard Medical School (National Institutes of Health/NIGMS Grant R01 GM084947), the Vienna Drosophila RNAi Center, and D. Williams and D. Bohmann. The monoclonal antibodies to actin (JLA20), Repo (8D12), and elav (9F8A9) were obtained from the Developmental Studies Hybridoma Bank, developed under the auspices of the National Institute of Child Health and Human Development and maintained by the University of lowa, Department of Biology, lowa City, lowa. Human tissue was obtained from the National Institute of Child Health and Human Development Brain and Tissue Bank for
}

pound identification that complement the conventional largescale in vitro compound screens are therefore warranted. Proper functioning of the nervous system relies on complex interdependent cellular and anatomic relationships among diverse cell types. Particularly for diseases affecting the brain, drug screening in vivo may therefore be advantageous. Further, in vivo screens will select for compounds able to pass the blood-brain barrier,

Developmental Disorders at the University of Maryland, Baltimore. We thank Professor E. van der Zee for the mouse monoclonal pan-mAChR antibody M35; and M. Brenner, J. Goldman, and M. Nedergaard for helpful discussions. The authors declare no competing financial interests.

Correspondence should be addressed to Dr. Mel B. Feany, Department of Pathology, Brigham and Women's Hospital, 77 Louis Pasteur Avenue, Room 630, Boston, MA 02115. E-mail: mel_feany@hms.harvard.edu. DOl:10.1523/JNEUROSCI.0256-15.2016

Copyright $\odot 2016$ the authors $\quad 0270-6474 / 16 / 361445-11 \$ 15.00 / 0$ 
which is a major hurdle in drug development for diseases affecting the CNS. The time and expense involved in testing compounds directly in the widely used murine models of disease makes such in vivo screens difficult despite their theoretical advantages. In contrast, Drosophila are small and cheap to culture. Many basic neuronal and glial functions are conserved in flies; and, accordingly, useful Drosophila models of a number of human neurological diseases have been developed (Feany and Bender, 2000; Wittmann et al., 2001; Jackson et al., 2002; Bonini and Fortini, 2003; Wang et al., 2011).

Here we use a model of Alexander disease to perform a moderate throughput in vivo chemical screen in Drosophila. Alexander disease is a rare neurological disorder caused by autosomal dominant mutations in the gene encoding the glial intermediate filament, glial fibrillary acidic protein (GFAP). Clinically, Alexander disease manifests with symptoms ranging from prominent seizures in younger patients to movement disorders in adults ( $\mathrm{Li}$ et al., 2005; Messing et al., 2012). The disease is inexorably progressive, and most patients die of end-stage neurological deterioration. There is no effective treatment. Pathologically, varying degrees of white matter loss and neurodegeneration are found. Of note, Alexander disease provides a unique example of glialmediated neurodegeneration because GFAP expression is predominantly astrocytic. In addition to variable degrees of neuronal and glial cell loss, all patients show aggregation of GFAP into eosinophilic, beaded inclusions, termed Rosenthal fibers, in astrocytes.

Given the autosomal dominant pattern of inheritance, the presence of abnormal protein aggregates, and recapitulation of disease-related phenotypes by overexpression (Messing et al., 1998; Brenner et al., 2001), but not knock-out (Gomi et al., 1995; Pekny et al., 1995) of GFAP in mice, a dominant gain-of-function mechanism, perhaps related to toxic protein aggregation, is postulated in Alexander disease (Messing et al., 2012). Thus, we modeled the disease in Drosophila by expressing wild-type and Alexander disease-linked mutant human GFAP in flies. To recapitulate the cellular specificity of GFAP expression, we expressed human GFAP in fly glia using the bipartite UAS/ GAL4 expression system (Brand and Perrimon, 1993) and the glial driver repo-GAL4.

Our model faithfully recapitulates multiple aspects of human Alexander disease, including aggregation of GFAP into inclusions strongly resembling Rosenthal fibers at the light and electron microscopic level, glial toxicity, non-cell-autonomous neuronal cell death, and seizures (Wang et al., 2011). Mutant GFAP, including the GFAP ${ }^{\mathrm{R} 79 \mathrm{H}}$ variant used in the current work, is significantly more toxic than wild-type GFAP, although, as in mice, wild-type GFAP will aggregate and produce toxicity at higher levels of expression (Messing et al., 1998).

Similarities to vertebrate systems are also apparent at the cell biological level. Both human and fly Rosenthal fiber inclusions contain $\alpha \mathrm{B}$-crystallin. As in mouse models of Alexander disease, overexpression of the fly homolog of $\alpha \mathrm{B}$-crystallin strongly ameliorates the behavioral and neuropathological defects of GFAP transgenic flies (Hagemann et al., 2009; Wang et al., 2011). Other pathways previously implicated in Alexander disease or in vertebrate models of the disorder, including oxidative stress, autophagy, JNK signaling, and glial glutamate transport, also show altered activity and contribute to pathology in the Drosophila model. These similarities support the use of our Drosophila model in the chemical screen described here aimed at identifying therapeutic compounds and pathways in Alexander disease.

\section{Materials and Methods}

Drosophila stocks. All fly crosses were performed at $25^{\circ} \mathrm{C}$; adults were aged at $29^{\circ} \mathrm{C}$ to increase transgene expression. repo-GAL4, da-GAL4, and UAS-G $\alpha q$ RNAi \#1 (\#30735) were from the Bloomington Drosophila Stock Center. The following stocks were obtained from Vienna Drosophila RNAi Center: UAS-mAChR-A RNAi \#1 (33123), UAS-mAChR-A RNAi \#2 (101407), and UAS-G $\alpha q$ RNAi \#2 (50729). Additional stocks used include UAS-CD8-PARP-Venus from D. Williams (Williams et al., 2006) and GstD1-lacZ from D. Bohmann (Sykiotis and Bohmann, 2008).

Transgenic mice. Six-month-old Gfap ${ }^{R 236 H /+}$ mice in the B6 background (Hagemann et al., 2006) were used for immunofluorescence staining and Western blotting of muscarinic receptor expression (see Fig. 6). Age-matched wild-type littermates were used as controls.

For chronic drug treatment, 6.5-week-old Gfap ${ }^{R 236 H /+}$ mice in the FVB background (Hagemann et al., 2006) were injected subcutaneously with saline or pirenzepine $(20 \mathrm{mg} / \mathrm{kg})$ twice daily for $10 \mathrm{~d}$; tissues were collected on day 11 when mice were $\sim 8$ weeks old (Ishibashi et al., 2014). Age-matched wild-type littermates were used as controls and treated with either saline or pirenzepine (see Fig. 8). For quantification of NRF2positive astrocytes, at least 50 astrocytes from the hippocampal CA1 region (coronal section 23 following the Mouse Brain Library, bregma: -2.92 mm; http://www.mbl.org/atlas170/atlas170_frame.html) were counted; 5 or 6 animals per genotype/treatment, both male (12 total) and female (11 total), were used.

All procedures were approved by the Institutional Animal Care and Use Committee of the Graduate School of the University of Wisconsin-Madison.

Human samples. Frozen frontal cortex white matter from 3 controls (mean age 14 years, range 1-28 years; 2 females and 1 male) and 3 Alexander disease patients (mean age 18 years, range 6-27 years; 1 female and 2 males) were obtained from the National Institute of Child Health and Human Development Brain and Tissue Bank for Developmental Disorders at the University of Maryland, Baltimore. GFAP mutations in the Alexander disease patients included R239C, K63E, and L359V. All cases had typical neuropathology of Alexander disease, including multiple Rosenthal fibers. Postmortem intervals were comparable between cases and controls and were $<24 \mathrm{~h}$ in all cases.

Drug feeding in Drosophila. All the compounds from the Spectrum Collection (MicroSource Discovery System) were obtained dissolved in DMSO at a concentration of $10 \mathrm{~mm} ; 30 \mu$ lof each compound was further diluted in water to a final concentration of $100 \mu \mathrm{M}$ and then mixed with instant Drosophila medium (Carolina Biological) for the primary screen. Controls were treated with DMSO only. The 7 compounds obtained from Sigma-Aldrich were dissolved in their optimal solvents suggested by the manufacturer's MSDS sheets (water for citalopram, dinitolmide, duloxetine, glycopyrrolate, and sulfanilate zinc; chloroform for $\beta$-sitosterol; and ethanol for praziquantel) to make stock solutions; $30 \mu$ l of each compound stock solution was further diluted in water at appropriate concentrations (Table 1) and then mixed with instant Drosophila medium (Carolina Biological) for dose-response analyses. Control flies were fed the appropriate concentration of solvent alone. Newly eclosed flies were raised on drug-embedded or solvent-embedded food for total of $3 \mathrm{~d}$ for GFAP level quantification and seizure quantification, $10 \mathrm{~d}$ for caspase activation analysis, and $15 \mathrm{~d}$ for TUNEL and oxidative stress analyses. Flies were transferred to new food every $3 \mathrm{~d}$.

Behavioral analysis. Flies were collected under $\mathrm{CO}_{2}$ anesthesia at $1 \mathrm{~d}$ after eclosion and kept at 5 animals per vial for $1 \mathrm{~d}$, without further anesthesia, before analysis. Drug-fed flies were kept on drug-embedded food for $3 \mathrm{~d}$ before analysis. For testing, vials were mechanically stimulated on a VWR mini-vortexer for $10 s$ at maximum speed (Ganetzky and Wu, 1982; Wang et al., 2011). The seizure frequency was calculated by dividing the number of flies with seizures by the total number of flies tested. Statistical significance was evaluated using the $\chi^{2}$ test.

Immunohistochemistry, immunofluorescence, and TUNEL analysis. Adult flies were fixed in formalin and embedded in paraffin; $4 \mu \mathrm{m}$ serial frontal sections were prepared through the entire fly brain and placed on a single glass slide. Mouse brains and human brain tissue were fixed in $4 \%$ PFA, embedded in paraffin, and sectioned at a thickness of $6 \mu \mathrm{m}$. 
Table 1. Compounds identified in the chemical screen ${ }^{a}$

\begin{tabular}{|c|c|c|c|c|}
\hline Drug & $\begin{array}{l}\text { Dose- } \\
\text { responsive }\end{array}$ & $\begin{array}{l}\text { Caspase } \\
\text { activation } \\
\text { (\% of control) }\end{array}$ & $\begin{array}{l}\text { Optimal } \\
\text { concentration } \\
(\mu \mathrm{m})\end{array}$ & Description \\
\hline$\beta$-Sitosterol & Yes & 37 & 500 & Plant sterol \\
\hline Citalopram & Yes & 59 & 50 & $\begin{array}{l}\text { Selective serotonin } \\
\text { reuptake inhibitor }\end{array}$ \\
\hline Dinitolmide & No & & & \\
\hline Duloxetine & Yes & 60 & 25 & $\begin{array}{l}\text { Serotonin-norepinephrine } \\
\text { reuptake inhibitor }\end{array}$ \\
\hline Glycopyrrolate & Yes & 62 & 50 & Anticholinergic \\
\hline Praziquantel & No & & & \\
\hline Sulfanilate zinc & No & & & \\
\hline
\end{tabular}

${ }^{a}$ Dose-response analysis $(0,10,25,50,100,250$, and $500 \mu \mathrm{m})$ for suppression of activated caspase in Alexander disease model flies showed that $\beta$-sitosterol, citalopram, duloxetine, and glycopyrrolate produce a dose-dependent reduction in the number of cleaved PARP-positive cells, whereas dinitolmide, praziquantel, and sulfanilate zinc do not. Higher drug doses did not show additional efficacy for any of the compounds. Control flies $(0 \mu \mathrm{m})$ were fed solvent (water for citalopram, dinitolmide, duloxetine, glycopyrrolate, and sulfanilate zinc; chloroform for $\beta$-sitosterol; ethanol for praziquantel)-embedded food. Flies were 10 -d-old and were treated with drug for $10 \mathrm{~d}$. $n \geq 6$ per concentration. Genotype: repo-GAL4, UAS-GFAPR79H, UAS-CD8-PARP-Venus /+.

For immunostaining, paraffin slides were processed through xylenes, ethanol, and into water. Antigen retrieval by boiling in sodium citrate, pH 6.0, was performed before blocking in PBS containing $0.3 \%$ Triton $\mathrm{X}-100$ and $2 \%$ milk for $1 \mathrm{~h}$. The following primary antibodies were used at the specified dilutions: PARP E51 (rabbit, 1:50,000, Abcam, ab32064), Repo (mouse, 1:5, DSHB), elav (mouse, 1:5, DSHB), $\beta$-galactosidase (mouse, 1:500, Promega, Z3781), mAChR M35 (mouse, 1:100, E. van der Zee), mAChR $_{1}$ (rabbit, 1:200, Frontier Institute), NRF2 (rat, 1:50, Cell Signaling Technology), and GFAP (mouse N206/8, 1:1000, University of California-Davis/National Institutes of Health NeuroMab Facility; rabbit, 1:10,000, Dako). For immunohistochemistry, biotin-conjugated secondary antibodies (1:200, Southern Biotechnology) and avidinbiotin-peroxidase complex (Vectastain Elite, Vector Laboratories) staining was performed using $\mathrm{DAB}$ (Vector Laboratories) as a chromagen. For double labeling, secondary antibodies coupled to Alexa- 488 or Alexa-555 (1:200, Invitrogen) were used.

Quantification of the number of cleaved poly (ADP-ribose) polymerase 1 (PARP)-positive cells was performed by counting the positive cells in serial frontal sections $(4 \mu \mathrm{m})$ of the entire brains from at least 6 animals per genotype and treatment. Quantification of the number of $\beta$-galactosidase-positive cells was performed by counting the positive cells in the optic lobe from at least 6 animals per genotype.

Apoptotic cell death was visualized using TUNEL according to the manufacturer's instructions (TdT FragEL DNA fragmentation kit, Calbiochem), with an additional avidin-biotin-peroxidase amplification step. The number of TUNEL-positive cells was counted by examining serial frontal sections $(4 \mu \mathrm{m})$ of the entire brains from at least 6 animals per genotype and treatment. Fluorescent TUNEL was performed using Alexa-488-conjugated streptavidin (Invitrogen).

Statistical analysis was performed using two-tailed $t$ test for two groups and one-way ANOVA with Tukey's multiple-comparison test for three or more groups. Each data point represents the mean \pm SEM.

Western blotting. Single adult Drosophila heads were homogenized in $1 \times$ Laemmli buffer (Sigma). For murine samples, corpus callosum was homogenized in Tris-saline buffer (50 mu Tris, $150 \mathrm{~mm} \mathrm{NaCl}$, pH 7.4, with protease inhibitor mixture; Thermo Scientific) and centrifuged at $300 \times g$ for $15 \mathrm{~min}$ at $4^{\circ} \mathrm{C}$. The supernatant was used for Western blotting. For human brains, white matter from frontal cortex was homogenized in Tris-saline buffer (50 mM Tris, $150 \mathrm{~mm} \mathrm{NaCl}, \mathrm{pH}$ 7.4, with protease inhibitor mixture; Thermo Scientific) and centrifuged at $100,000 \times g$ for $1 \mathrm{~h}$ at $4^{\circ} \mathrm{C}$. The supernatant was used for Western blotting. Samples were boiled for $5 \mathrm{~min}$ at $100^{\circ} \mathrm{C}$ and subjected to SDS-PAGE using $10 \%$ or $4 \%-12 \%$ gels (Lonza). Proteins were transferred to nitrocellulose membranes (Bio-Rad), blocked in 2\% milk in PBS with $0.05 \%$ Tween 20, and immunoblotted using the following primary antibodies: GFAP (rabbit, 1:10 ${ }^{7}$, Dako, Z0334), actin JLA20 (mouse, 1:4000, DSHB), mAChR $M_{1}$ (rabbit, 1:4000, Frontier Institute), and GAPDH (rabbit, 1:100,000, Abcam). The appropriate anti-mouse or anti-rabbit HRP-

\section{1,987 compounds}
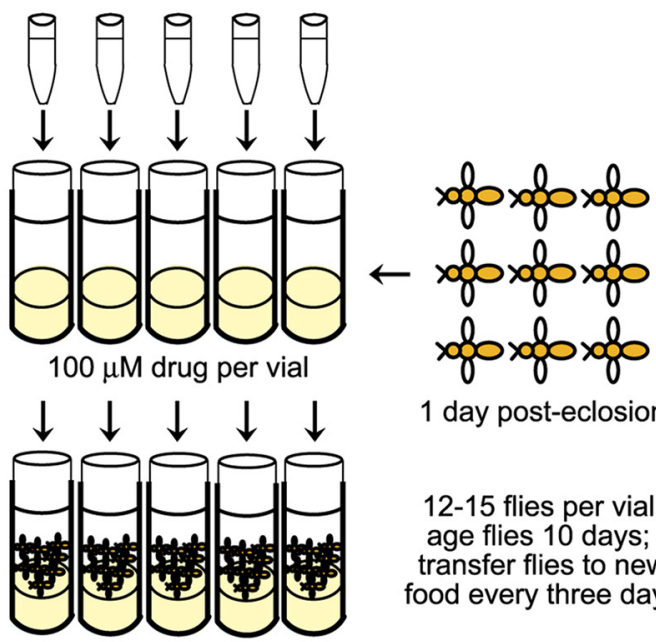

1 day post-eclosion

12-15 flies per vial; age flies 10 days; transfer flies to new food every three days

\section{$\downarrow \downarrow \downarrow \downarrow \downarrow$ \\ $\varnothing \varnothing \infty \quad \infty \quad$ Embed heads in paraffin}
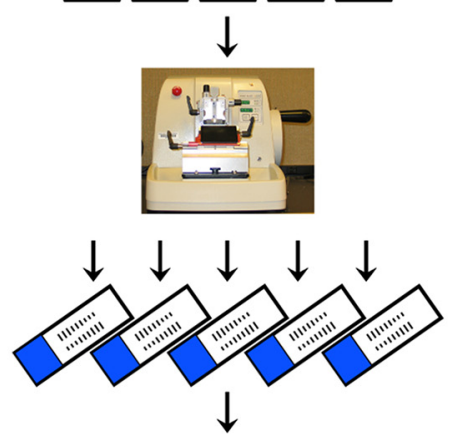

IHC staining for caspase activation

4 compounds with dose-responsive suppression of GFAP toxicity

Figure 1. Screen design and results. Each compound from the Spectrum Collection was mixed with instant Drosophila medium individually at a final concentration of $100 \mu \mathrm{m}$. Oneday-old Alexander disease model flies carrying a transgenic caspase reporter (repo-GAL4, UASGFAP ${ }^{R 79 H}$, UAS-CD8-PARP-Venus /+) were raised on drug-embedded food for a total of $10 \mathrm{~d}$, with transfer to a vial with fresh drug-embedded food every $3 \mathrm{~d}$. Caspase activation was then monitored by determining the number of cleaved PARP-positive cells in the brain using immunohistochemical (IHC) detection on sections from paraffin-embedded material.

conjugated secondary antibody (1:50,000, Southern Biotechnology) was applied, and signal was detected with West Femto chemiluminescent substrate (Thermo Scientific). All blots were repeated at least three times, and representative blots are presented in the figures.

Confocal microscopy. All the fluorescent images were taken as $Z$-stacks on a Leica SP $8 \times$ confocal microscope at Harvard NeuroDiscovery Center Enhanced Neuroimaging Core facility or an Olympus FV1000 confocal microscope at Harvard Neurobiology Imaging Facility. All the images were visualized in $2 \mathrm{D}$ projections of $Z$-stacks. Control and experimental samples were imaged with the same laser setting and the same $Z$-stack thickness.

Real-time PCR. RNA was isolated from Drosophila head homogenates using QIAzol (QIAGEN) and reverse-transcribed with the HighCapacity cDNA Reverse Transcription kit (Applied Biosystems) according to the manufacturer's instructions. Real-time PCR was performed and monitored using SYBR Green PCR Master Mix (Applied Biosystems) in a StepOnePlus Real-Time PCR system (Applied Biosystems) according to the manufacturer's instructions. Drosophila ribosomal protein $R p L 32$ was used as a control. Statistical analysis was performed using one-way ANOVA with Tukey's multiple-comparison test. Each data point represents the mean \pm SEM. 
Primers are as follows: $m A C h R-A$, CATCG AGTAGTTGTCCCGCATC; GAGCAGGAG GAGCCTTCTGATT; $G \alpha q$, GCCGCGAGCT TAAACTGCT; CCAGCTTGATGTACCCAC GC; and RpL32, GACCATCCGCCCAGCAT AC; CGGCGACGCACTCTGTT.

Statistical analysis. Values are presented as mean \pm SEM. GraphPad Prism 5 software was used for all statistical analysis. Chi-square test was used for seizure behavioral analysis. For others, unpaired $t$ test was used for two groups and one-way ANOVA with Tukey's multiplecomparison test for three or more groups. A minimum of 6 animals per genotype and treatment was used to for caspase activation, cell death (TUNEL), and oxidative stress reporter assays. A minimum of 100 animals per genotype and treatment was used for seizure assays. All Western blots and RT-PCR determinations were repeated at least three times, and a representative blot was shown. The optimal concentrations of candidate compounds was determined by dose-response analysis.

\section{Results}

Chemical screen identifies compounds ameliorating GFAP toxicity in

\section{Alexander disease model flies}

To identify therapeutic compounds for Alexander disease, we performed a chemical screen of 1987 compounds from the Spectrum Collection (MicroScource Discovery System) in our Drosophila model of Alexander disease. To monitor GFAP toxicity under screening conditions, we used a transgenic caspase reporter, UAS-CD8$P A R P-V e n u s$, which consists of the extracellular and transmembrane domain of mouse CD8 fused to 40 amino acids from human PARP, including the caspase cleavage site, and Venus, a yellow fluorescent protein variant. Caspase activation can be detected using an antibody specific for the cleaved form of human PARP (Williams et al., 2006). Alexander disease model flies carrying the caspase reporter (repo-GAL4, UAS-GFAP ${ }^{R 79 H}, U A S$ CD8-PARP-Venus/+) were raised on drug-embedded Drosophila culture media at a final compound concentration of $100 \mu \mathrm{M}$ for a total of $10 \mathrm{~d}$. Flies were transferred to a new vial with fresh drugembedded medium every 3 d (Fig. 1). Because available ELISA assays displayed insufficient sensitivity and specificity in our model, immunohistochemistry on sections taken through entire fly brains was used to monitor caspase activation (the number of cleaved PARP-positive cells) in the glia of drug-treated flies. Drugs that led to $\geq 75 \%$ reduction in caspase activation were selected as initial hits. Suppression of activated caspase was confirmed by repeat analysis on the first set of drug-fed flies and then by feeding compounds to a second group of animals. Seven compounds were confirmed in the second round of drug feeding (Table 1). These seven compounds were purchased from SigmaAldrich, and a dose-response analysis was performed. Four compounds ( $\beta$-sitosterol, citalopram, duloxetine, and glycopyrrolate) were confirmed to reduce caspase activation in $\mathrm{GFAP}^{\mathrm{R} 79 \mathrm{H}}$ transgenic flies. Three compounds did not show statistically significant rescue of toxicity or did not do so in a dose-dependent manner (Table 1).

Among the four compounds that showed a dose-dependent reduction in caspase activation, glycopyrrolate is an antagonist targeting the mAChR. mAChRs are expressed in astrocytes and
B
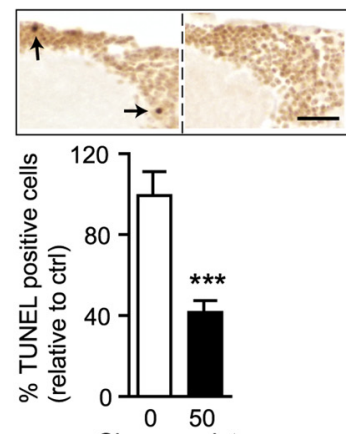

Glycopyrrolate conc. $(\mu \mathrm{M})$
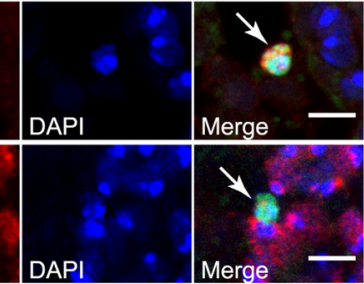

av $\quad$ DAPI
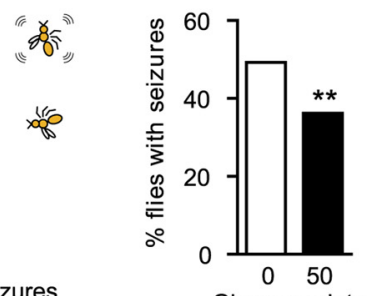

Glycopyrrolate conc. $(\mu \mathrm{M})$

Figure 2. Glycopyrrolate reduces GFAP toxicity in Alexander disease model flies. $\boldsymbol{A}$, Double-label immunofluorescence reveals at $50 \mu \mathrm{m} .{ }^{* *} p<0.001$ (two-tailed $t$ test). $n \geq 6$ per concentration. Flies were 15 -d-old and were treated with drug for $15 \mathrm{~d}$ Genotype: repo-GAL4, UAS-GFAP ${ }^{R 79 H /+}$. Control flies were treated with solvent (water) only. Arrows indicate TUNEL-positive cells. 100 per concentration. Flies were 3-d-old and were treated with drug for $3 \mathrm{~d}$. Genotype: repo-GAL4, UAS-GFAP ${ }^{R 79 H /+}$. Control (ctrl) flies were treated with solvent (water) only. The schematic represents the method for seizure induction.

can modulate important cellular functions, including $\mathrm{Ca}^{2+}$ homeostasis and proliferation (Guizzetti et al., 1996; Porter and McCarthy, 1997; Navarrete et al., 2012). To investigate further the actions of glycopyrrolate on toxicity in our Alexander disease model, we examined cell death and seizures. We observed both glial and neuronal cell death in our Alexander disease model flies (Fig. 2A). We found that glycopyrrolate significantly reduced the total number of TUNEL-positive cells and the percentage of flies with seizures (Fig. $2 B, C$ ). To ensure that glycopyrrolate did not simply reduce transgenic expression of GFAP ${ }^{\mathrm{R} 79 H}$, we performed Western blots on drug-fed flies. We found no reduction in GFAP levels in the presence of therapeutic levels of glycopyrrolate (Fig. $3 J$ ).

\section{mAChR signaling controls GFAP toxicity in vivo}

To confirm the role of $\mathrm{mAChR}$ signaling in promoting toxicity in our Alexander disease model, we tested two other mAChR antagonists, atropine and scopolamine. Consistent with the beneficial effects of glycopyrrolate, both atropine and scopolamine rescued caspase activation in a dose-dependent manner in GFAP ${ }^{\mathrm{R} 79 \mathrm{H}}$ transgenic flies, with optimal concentrations of 100 and $50 \mu \mathrm{M}$, respectively (Fig. $3 A, B$ ). To determine whether activating $\mathrm{mAChR}$ signaling would increase GFAP ${ }^{\mathrm{R} 79 \mathrm{H}}$ toxicity, we fed flies pilocarpine, an $\mathrm{mAChR}$ agonist. We found a significant, dosedependent increase in caspase activation in Alexander disease model flies, with an optimal concentration of $500 \mu \mathrm{M}$ (Fig. $3 C$ ). Importantly, pilocarpine did not activate caspase in control flies without human GFAP ${ }^{\mathrm{R} 79 H}$ expression (data not shown). Furthermore, atropine and scopolamine significantly reduced, whereas pilocarpine increased, the number of TUNEL-positive cells and the percentage of flies with seizures in the brains of Alexander disease model flies (Fig. 3D-I). Pilocarpine did not induce cell death, as monitored by TUNEL staining, in control 
A

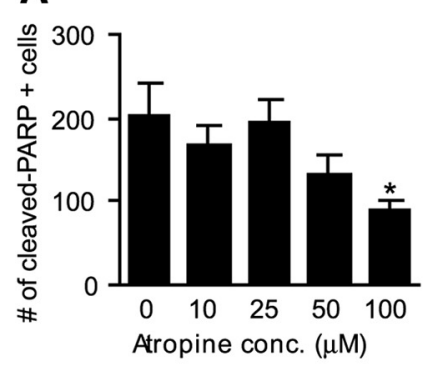

D
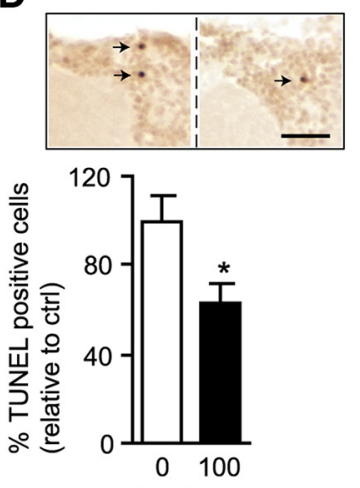

Atropine

conc. $(\mu \mathrm{M})$
B

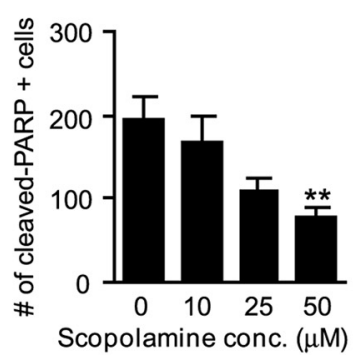

C

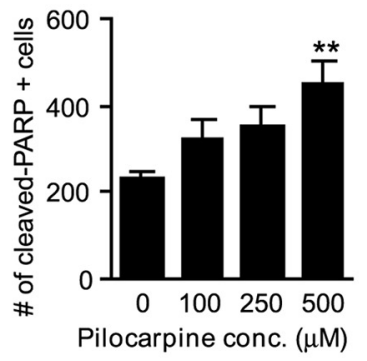

E
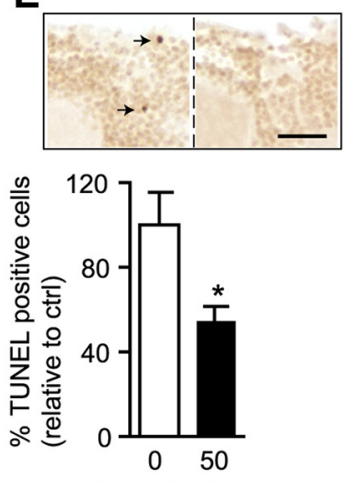

Scopolamine conc. $(\mu \mathrm{M})$
G

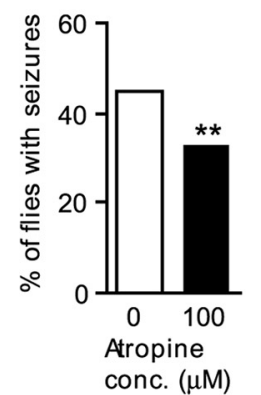

H

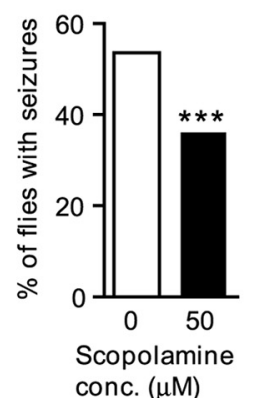

$\mathbf{F}$

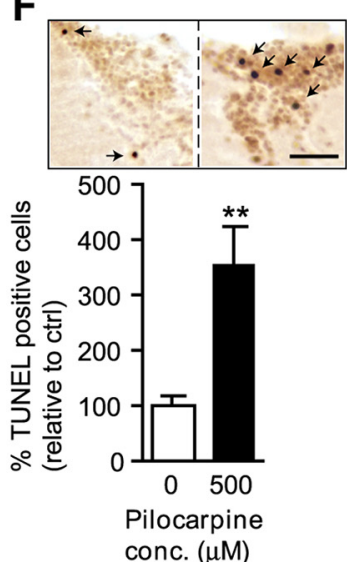

I J

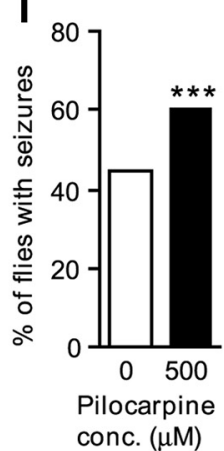

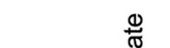

$\stackrel{\frac{0}{6}}{\frac{0}{6}}$

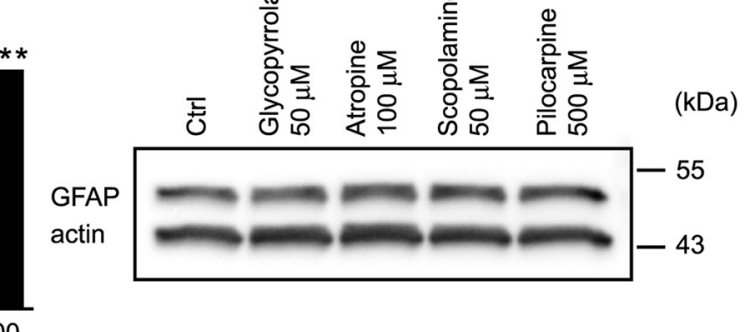

(kDa)

.

Figure 3. Compounds inhibiting mAChR reduce GFAP toxicity in Alexander disease model flies. A-C, Dose-response analysis of three compounds targeting mAChR. $m A C h R$ antagonists, atropine $(\boldsymbol{A})$ and scopolamine $(\boldsymbol{B})$ reduce the number of cleaved PARP-positive cells in a dose-dependent manner, whereas the agonist, pilocarpine $(\boldsymbol{C})$, increases the number of cleaved PARP-positive cells in a dose-dependent manner. ${ }^{*} p<0.05$ (one-way ANOVA with Tukey's multiple-comparison test). ${ }^{* *} p<0.01$ (one-way ANOVA with Tukey's multiple-comparison test). $n \geq 6$ per concentration. Flies were 10-d-old and were treated with drugs for $10 \mathrm{~d}$. Genotype: repo-GAL4, UAS-GFAPR79H, UAS-CD8-PARP-Venus/+. D-F, Cell death analysis in mAChR compound-fed flies. Atropine (D) and scopolamine $(\boldsymbol{E})$ significantly reduce, whereas pilocarpine $(\boldsymbol{F})$ increases, the number of TUNEL-positive cells in Alexander disease model flies. ${ }^{*} p<0.05$ (two-tailed $t$ test). ${ }^{* *} p<0.01$ (two-tailed $t$ test). $n \geq 6$ per concentration. Flies were 15-d-old and were treated with drugs for $15 \mathrm{~d}$. Genotype: repo-GAL4, UAS-GFAP ${ }^{R 79 H /+}$. Ctrl: solvent (water)-fed flies. Arrows indicate TUNEL-positive cells. Scale bar, $20 \mu \mathrm{m}$. G-I, Seizure analysis in mAChR compound-fed flies. Atropine $(\boldsymbol{G})$ and scopolamine $(\boldsymbol{H})$ reduce, whereas pilocarpine $(\boldsymbol{I})$ increases, the percentage of flies with seizures. ${ }^{* *} p<0.01$ $\left(\chi^{2}\right.$ test). ${ }^{* * *} p<0.001$ ( $\chi^{2}$ test). $n>100$ per concentration. Flies were 3-d-old and were treated with drugs for 3 d. Genotype: repo-GAL4,UAS-GFAP ${ }^{R 79 H /+}$.J, Western blot shows equivalent GFAP protein levels in control (ctrl) and drug-fed flies. Flies were 3-d-old and were treated with drug for $3 \mathrm{~d}$. The blot was reprobed with an antibody for actin to illustrate equivalent protein loading. Genotype: repo-GAL4, UAS-GFAP ${ }^{R 79 H /+}$. Control (Ctrl) flies were treated with solvent (water) only.

flies without human GFAP ${ }^{\mathrm{R} 79 \mathrm{H}}$ expression (data not shown). As for glycopyrrolate, modulation in GFAP toxicity by other compounds targeting mAChR was not due to alterations in GFAP levels (Fig. 3J). Together, these data strongly suggest that mAChR signaling, as probed with well-characterized small molecules, plays a key role in modulating GFAP toxicity in vivo.

We have previously described a critical role for oxidative stress in mediating toxicity in Alexander disease model flies (Wang et al., 2011). To explore the mechanism by which compounds targeting $\mathrm{mAChR}$ signaling modified GFAP toxicity, we used an oxidative stress reporter, GstD1-lacZ (Sykiotis and Bohmann, 2008), whose activation can be detected by immunostaining for $\beta$-galactosidase (Fig. 4A). In Alexander disease model flies carry- ing the GstD1 oxidative stress reporter, we observed that atropine and scopolamine significantly decreased the reporter activation, whereas pilocarpine markedly increased the reporter activation, suggesting that mAChR signaling influences GFAP toxicity via oxidative stress (Fig. $4 B-D$ ).

\section{Genetic inhibition of $\mathrm{mAChR}$ signaling reduces GFAP toxicity}

The Drosophila genome contains one well-characterized mAChR, mAChR-A, which has a high degree of amino acid similarity and a pharmacological profile similar to mammalian mAChRs (Onai et al., 1989; Shapiro et al., 1989; Millar et al., 1995). To probe the role of $\mathrm{mAChR}$ signaling genetically in our Alexander disease 
model, we reduced the expression of mAChR-A in GFAP ${ }^{\mathrm{R} 79 \mathrm{H}}$ transgenic flies using two independent transgenic RNAi lines. We observed a significant reduction of the number of TUNEL-positive cells with reduced mAChR-A levels (Fig. 5A). The rescue of GFAP toxicity was not due to lower levels of GFAP protein (Fig. 5D). To confirm the expected reduction in transcript levels by RNAi targeting $m A C h R-A$, we performed RT-PCR and observed significantly reduced $m A C h R-A$ mRNA levels compared with controls (Fig. 5E). Consistent with rescue of cell death, the number of flies with seizures was also markedly reduced by reducing the expression of $m A C h R-A$ (Fig. 5B). Mechanistically, reduction of $m A C h R-A$ expression also decreased the activation of oxidative stress reporter in Alexander disease model flies, consistent with an effect of oxidative stress downstream of $\mathrm{mAChR}$ signaling (Fig. 5C).

mAChRs are G-protein-coupled receptors. In mammals, there are five subtypes of $\mathrm{mAChRs}\left(\mathrm{M}_{1-5}\right)$ and they preferentially couple to different G-proteins and signal through various effectors (Felder, 1995; Nathanson, 2000; Wess et al., 2007). In Drosophila, mAChR-A has been shown to mediate $\mathrm{Ca}^{2+}$ release through $\mathrm{G} \alpha \mathrm{q}-\mathrm{Plc} \beta$ signaling in neurons (Agrawal et al., 2013). To test whether mAChR-A also signals through $\mathrm{G} \alpha \mathrm{q}$ to modulate GFAP toxicity in glia in our Alexander disease model, we reduced the expression of $G \alpha q$ using two independent transgenic RNAi lines and observed significant decreases in the number of TUNELpositive cells in GFAP ${ }^{\mathrm{R} 79 \mathrm{H}}$ transgenic flies, but no change in GFAP protein levels (Fig. $5 F, I$ ). The reduction of $G \alpha q$ mRNA transcript levels by two RNAi lines was significant as measured by RT-PCR (Fig. 5J). Consistent with rescue of cell death, the percentage of flies with seizures was also markedly reduced by the reduction of $G \alpha q$ in Alexander disease model flies (Fig. 5G). Reduction of $G \alpha q$ expression also decreased the activation of oxidative stress reporter in Alexander disease model flies (Fig. $5 H$ ). Together, these data support the hypothesis that $\mathrm{G} \alpha \mathrm{q}$ is a downstream mediator for $\mathrm{mAChR}$-A signaling in modulation of GFAP toxicity and acts via oxidative stress.

\section{Increased $\mathrm{mAChR}$ expression in Alexander disease model mice and in patients}

Because reduction of $\mathrm{mAChR}$ signaling was protective in the Drosophila model of Alexander disease, to increase the translational relevance of our findings, we next investigated a potential role for $\mathrm{mAChRs}$ in mammalian systems. We began by assessing expression of mAChRs using a well-characterized and widely used panmAChR antibody, M35 (van der Zee and Luiten, 1999), in Alexander disease model mice $\left(G f a p^{R 236 H /+}\right)$. These mice have been engineered by homologous recombination to express the equivalent of the common and deleterious human R239H mutant form of GFAP and develop clinical and pathological features reminiscent of human Alexander disease (Hagemann et al., 2006). We observed significantly increased immunoreactivity for

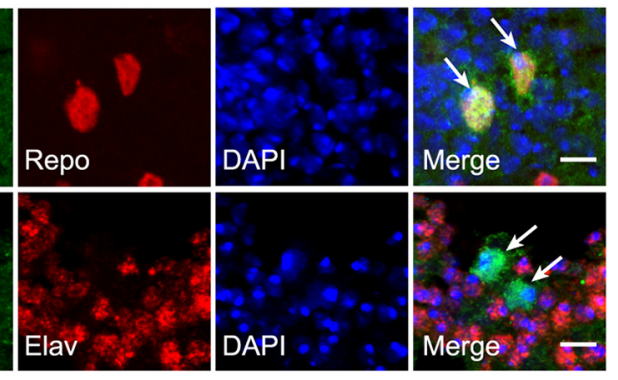

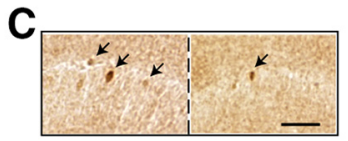

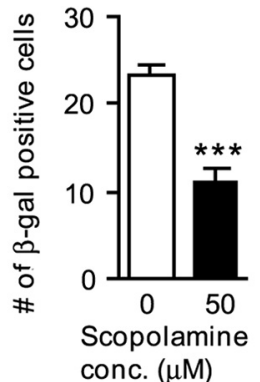

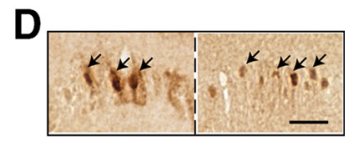

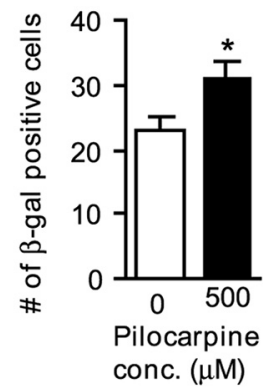

Figure 4. $\mathrm{mAChR}$ compounds modulate oxidative stress in Alexander disease model flies. $\boldsymbol{A}$, Double-label immunofluorescence shows activation of the oxidative stress reporter, GstD1-lacZ, in glial cells (arrows) of Alexander disease model flies. Repo marks increases, the number of $\beta$-galactosidase-positive cells in Alexander disease model flies. ${ }^{*} p<0.05$ (two-tailed $t$ test). ${ }^{* * *} p<0.001$ (two-tailed $t$ test). $n \geq 6$ per concentration. Flies were 15-d-old and were treated with drugs for $15 \mathrm{~d}$. Genotype: GstD1-lacZ/+; repo-GAL4, UAS-GFAPR79H/+ . Arrows indicate $\beta$-galactosidase-positive cells. Scale bar, $20 \mu \mathrm{m}$.

M35 in the astrocytes of 6-month-old Gfap ${ }^{R 236 H /+}$ mice compared with wild-type littermate controls (Fig. 6A, arrows). To investigate the subtype of muscarinic cholinergic receptor upregulated in Alexander disease model mice, we performed immunostaining using a previously validated $\mathrm{M}_{1}$-subtype specific antiserum (Narushima et al., 2007; Yamasaki et al., 2010; Anisuzzaman et al., 2013). $\mathrm{M}_{1}$ receptors are the predominant $\mathrm{mAChR}$ subtype expressed in cerebral cortex and hippocampus. We observed increased expression of $\mathrm{M}_{1}$ receptors in the astrocytes of 6-month-old Gfap $p^{R 236 H /+}$ mice (Fig. 6B, arrows). Consistent with immunostaining results, a significant increase of $M_{1}$ receptor expression in the corpus callosum was detected by Western blotting in 6-month-old Gfap $p^{R 236 H /+}$ mice compared with wild-type littermate controls (Fig. 6C). With both antibodies, we observed some plasma membrane staining along with prominent punctate cytoplasmic staining, as has been described previously (Anisuzzaman et al., 2013; Uwada et al., 2014).

To extend our studies to the human disease itself, we next investigated $M_{1}$ receptor expression in the postmortem brain tissue from Alexander disease patients. We observed increased expression of $M_{1}$ receptors in the astrocytes of Alexander disease patients compared with controls using both double-label immunofluorescence (Fig. 7A, arrows) and Western blotting (Fig. 7B).

Finally, to test the effect of muscarinic antagonism in our mammalian system, we treated Alexander disease model mice with pirenzepine (Ishibashi et al., 2014), an $\mathrm{M}_{1}$ antagonist, for $10 \mathrm{~d}$. We investigated the effect of pharmacological $\mathrm{M}_{1}$ inhibition on NRF2, an oxidative stress-responsive transcription factor induced in mouse models of Alexander disease (Hagemann et al., 
A

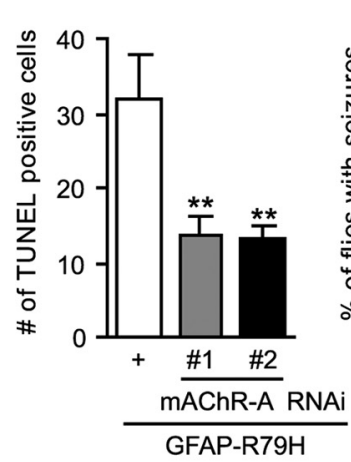

D
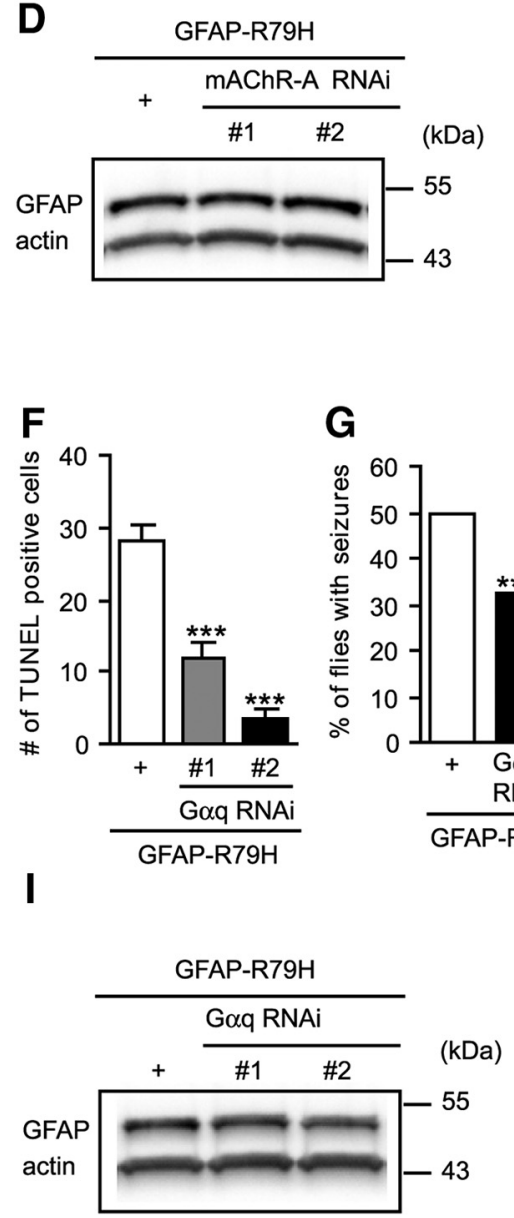

B

G
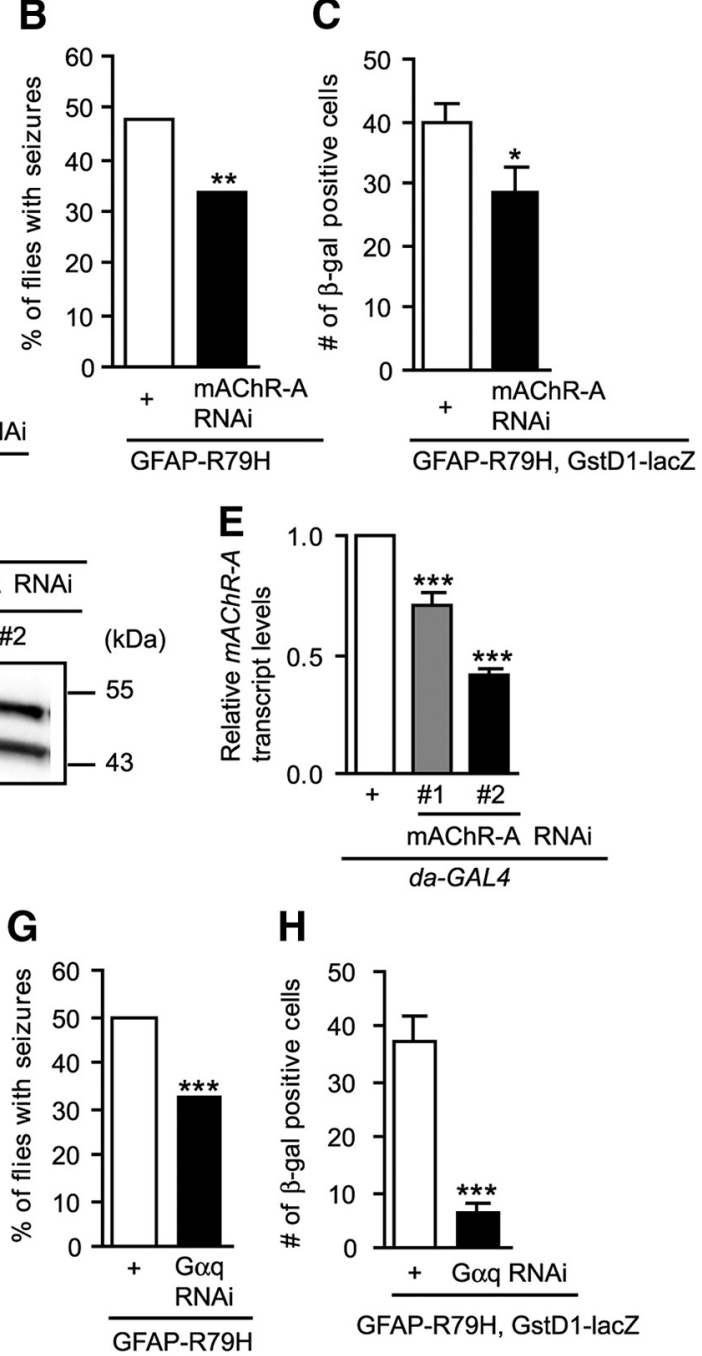

H

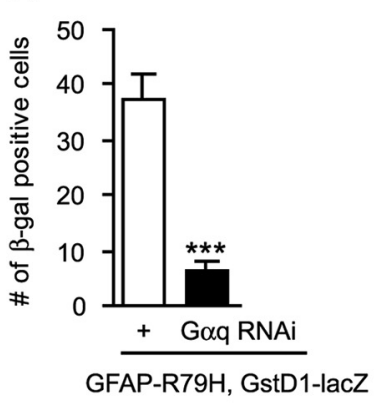

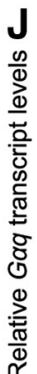

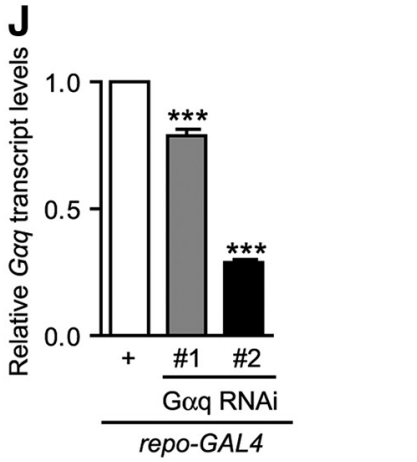

Figure 5. Genetic inhibition of $m A C h R$ pathway reduces GFAP toxicity in Alexander disease model flies. In all panels, GFAP-R79H indicates repo-GAL4, UAS-GFAP ${ }^{R 79 H /+}$. mAChR-A RNAi indicates UAS-mAChR-A RNAi $(\boldsymbol{A}-\boldsymbol{E})$, and G $\alpha q$ RNAi indicates UAS-G $\alpha q$ RNAi $(\boldsymbol{F}-\boldsymbol{J}) . \boldsymbol{A}, \boldsymbol{F}$, Reducing expression of mAChR-A or $\mathrm{G} \alpha \mathrm{q}$ with transgenic RNAi significantly reduces the number of TUNELpositive cells. ${ }^{* *} p<0.01$. ${ }^{* * *} p<0.001 . n \geq 6$ per genotype. Control (+): repo-GAL4, UAS-GFAP ${ }^{R 79 H /+}$. B, G, Reducing expression of mAChR-A or $\mathrm{G} \alpha \mathrm{q}$ significantly decreases the percentage of flies with seizures. ${ }^{* *} p<0.01$. ${ }^{* * *} p<0.001 . n>100$ per genotype. Control (+): repo-GAL4, UAS-GFAP ${ }^{R 79 H /+}$. C, H, Decreased expression of mAChR-A or G $\alpha$ q reduces the number of $\beta$-galactosidase-positive cells in Alexander disease model flies. ${ }^{*} p<0.05 .{ }^{* * *} p<0.001 . n \geq 6$ per genotype. Control $(+)$ : GstD1-lacZ/+; repo-GAL4, UAS-GFAP $P^{R 79 H /+}$. D, I, Western blots demonstrate equivalent GFAP levels in GFAP ${ }^{R 79 H}$ transgenic flies alone and in combination with mAChR-A RNAi or G $\alpha$ q RNAi lines. The blots were reprobed with an antibody to actin to illustrate equivalent protein loading. Control (+): repo-GAL4, UAS-GFAPR79H/+.$E$, J, RT-PCR shows reduced $m A C h R-A$ and $G \alpha q$ mRNA levels in transgenic RNAi lines, using da-GAL4 or repo-GAL4 as drivers. Rp/32 was used as a control. ${ }^{* * *} p<0.001 . n=3$ biological replicates. Control (+): da-GAL4/+ (E) and repo-GAL4/+ (J). $\boldsymbol{A}, \boldsymbol{C}, \boldsymbol{F}, \boldsymbol{H}$, Flies were 20-d-old. $\boldsymbol{B}, \boldsymbol{D}, \boldsymbol{E}, \boldsymbol{G}, \boldsymbol{I}, \boldsymbol{J}$, Flies were 1-d-old. Statistical tests: $\boldsymbol{A}, \boldsymbol{E}, \boldsymbol{F}, \boldsymbol{J}$, one-way ANOVA with Tukey's multiple-comparison test; $\boldsymbol{B}, \boldsymbol{G}, \chi^{2}$ test; $\boldsymbol{C}, \boldsymbol{H}$, two-tailed $t$ test.

2005, 2009). With double-label immunofluorescence, we observed a significant reduction in the number of NRF2-positive astrocytes in pirenzepine-treated compared with saline-treated Alexander disease model mice (Fig. 8).

\section{Discussion}

Here we describe an unbiased screen of 1987 compounds in a Drosophila model of Alexander disease, a unique and clinically severe glial-based neurological disorder for which there is currently no effective treatment. A notable feature of our screening strategy was immunohistochemical detection of caspase activity on brain sections as a marker of cellular toxicity. Prior chemical screens of similar scale have been reported in Drosophila but have typically relied on simple behavioral or reporter assays, often in more easily manipulated embryonic or larval stages of development (Chang et al., 2008; Gasque et al., 2013; Markstein et al., 2014). Because Drosophila is now more commonly being used to model complex, agedependent diseases (Feany and Bender, 2000; Wittmann et al., 2001; Colodner and Feany, 2010; Wang et al., 2011), the need to screen for alterations in phenotypes best assayed with the precision of histological analysis may increasingly emerge. We demonstrate here that such histological screening is feasible on the scale of thousands of compounds.

A potential caveat to screening based on histology is the possibility that compounds may be identified that rescue the histological phenotype, but not improve overall health or behavior of the animal. Our findings, that a signaling pathway identified first through histological screening significantly alters seizure frequency in our GFAP ${ }^{\mathrm{R} 79 \mathrm{H}}$ transgenic fly model of Alexander disease, suggest that efficacious treatments can emerge from a primary histological screen. Our prior experience with genetic modifiers in the Alexander disease model (Wang et al., 2011) and other models of human disease further supports a strong correlation between tissue neuropathology, behavior, and lifespan (Feany and Bender, 2000; Wittmann et al., 2001; Colodner and Feany, 2010).

As in previous moderate throughput screens, we attempted to enrich for clinically relevant hits by screening the Spectrum Compound library, which contains many FDA-approved drugs and natural products. So-called "repurposing" of drugs is a strategy used to decrease the cost and risk of drug discovery. Because exist- 
A

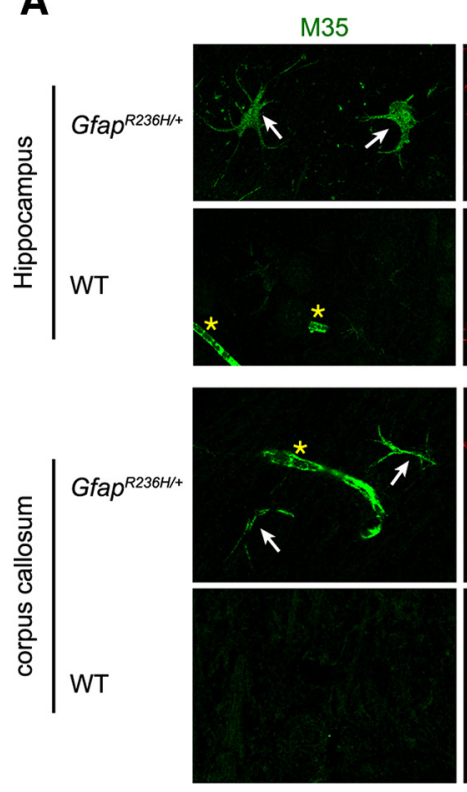

GFAP
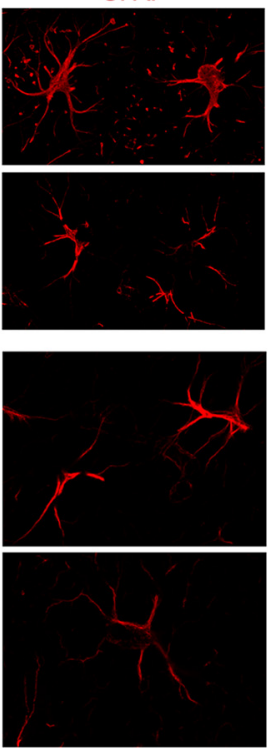

DAPI
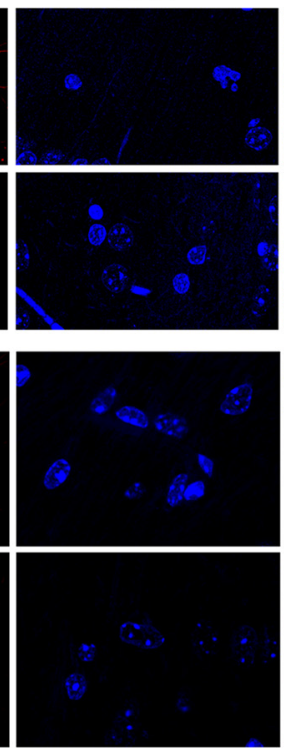

M35/GFAP/DAPI
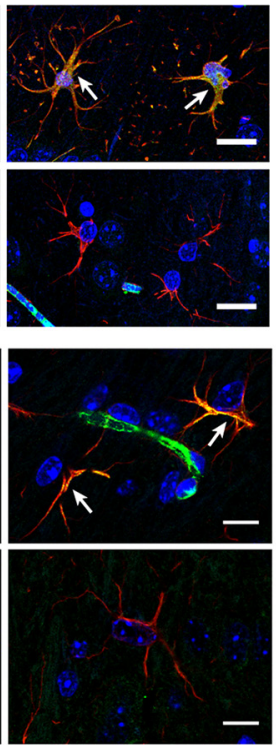

B
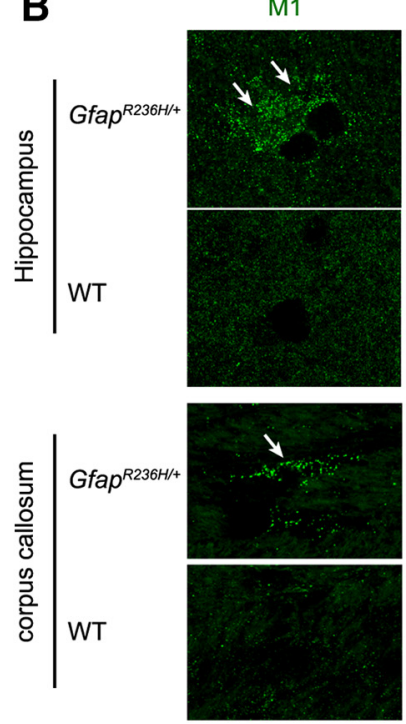

GFAP
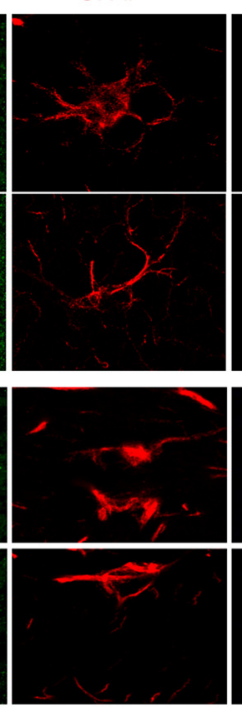

DAPI
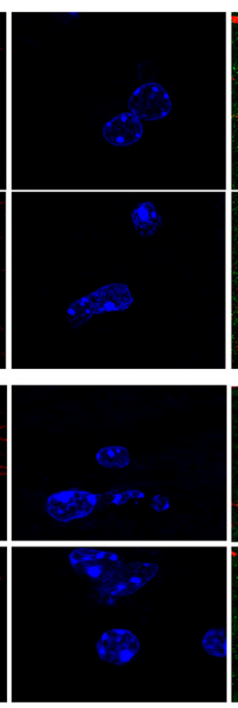

M1/GFAP/DAPI
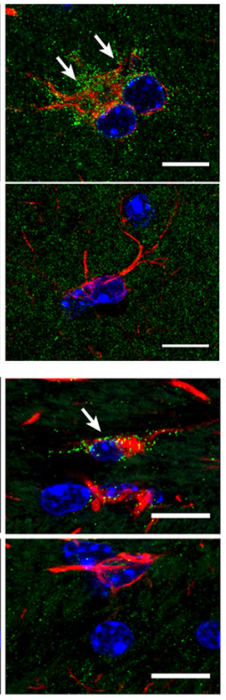

C
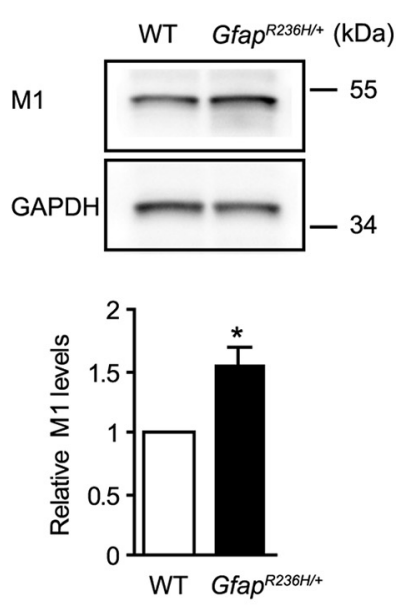

Figure 6. Increased mAChRs in astrocytes of Alexander disease model mice. $A$, Double-label immunofluorescence reveals increased immunostaining with pan-mAChR antibody, M35, in the astrocytes of 6-month-old GFAPR239H/+ mice (arrows). GFAP is an astrocytic marker. Asterisks show blood vessels. DAPI labels nuclei. Scale bar, $20 \mu \mathrm{m}$. B, Double-label immunofluorescence reveals upregulation of the $\mathrm{M}_{1}$ receptor in astrocytes of 6-month-old $G F A P^{R 239 H /+}$ mice (arrows). DAPI labels nuclei. Scale bar, $10 \mu \mathrm{m}$. C, Western blot demonstrates increased expression of $\mathrm{M}_{1}$ receptor in the corpus callosum of 6-month-old GFAP ${ }^{R 236 H /+}$ mice. The blot was reprobed with an antibody to GAPDH to illustrate equivalent protein loading. $n=4$ biological replicates. ${ }^{*} p<0.05$ (two-tailed Student's $t$ test).

ing drugs have known pharmacokinetic and safety profiles, they can be evaluated rapidly in Phase II clinical trials, thus saving significant development costs (Chong and Sullivan, 2007). In addition, many of the compounds in the Spectrum Compound library are known to cross the blood-brain barrier efficiently, a critical roadblock in the conventional drug discovery pipeline. We indeed identified two pathways, muscarinic cholinergic signaling and serotonin reuptake, for which there are effective, FDA-approved drugs with documented penetration into the CNS.

To validate cholinergic signaling as a therapeutic target in Alexander disease, we extended our screening results, taking advantage of both the strengths of Drosophila genetics and the increased translational relevance of mammalian systems. We provide strong support for a signaling cascade involving $\mathrm{G} \alpha \mathrm{q}$ and oxidative stress downstream of mAChR-A signaling in mediating
GFAP toxicity using a genetic approach in flies, although lack of suitable antibody reagents limited our ability to assess receptor levels directly in the Drosophila system. In a complementary approach in a mouse model of Alexander disease and in patient brain tissue, we documented increased expression of mAChRs, consistent with a protective effect of downregulating $\mathrm{mAChR}$ expression genetically in flies and pharmacological blockade of $\mathrm{M}_{1}$ receptors in mice. The mechanism by which $\mathrm{mAChR}$ expression is altered in Alexander disease is not clear. However, upregulation of mAChRs has been observed in the context of inflammation (Español et al., 2014), and previous studies have demonstrated a robust stress response in the brains of Alexander disease model mice (Hagemann et al., 2005, 2006, 2009), including upregulation of multiple inducible cytokines and their receptors (Hagemann et al., 2005). 
A

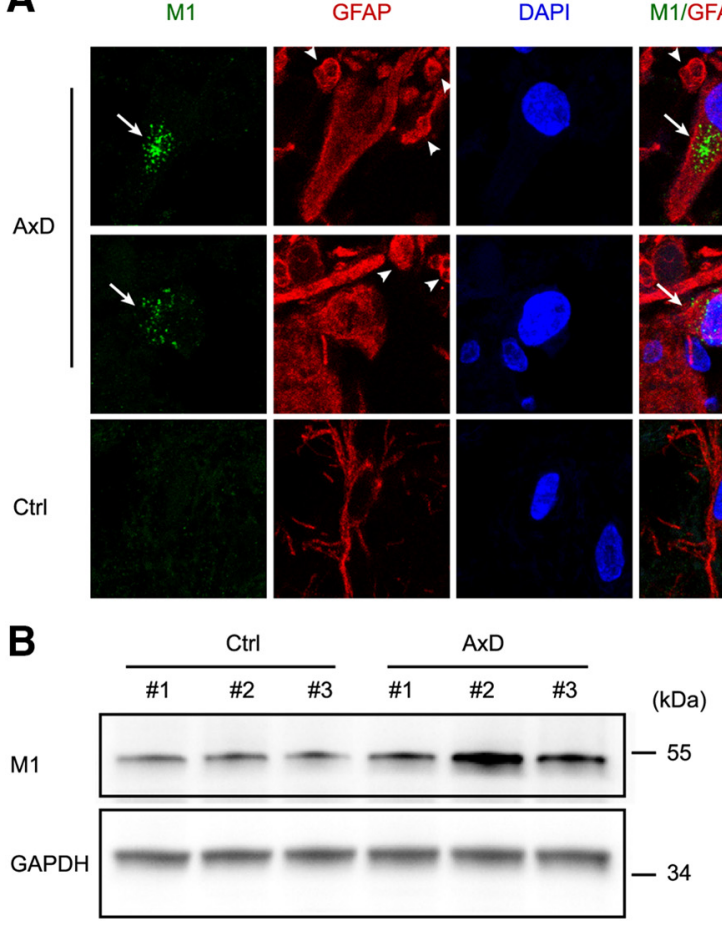

M1/GFAP/DAPI

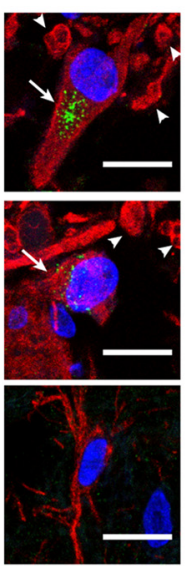

Figure 7. Increased expression of $M_{1}$ receptor in Alexander disease patients. $\boldsymbol{A}$, Double-label immunofluorescence reveals upregulation of $\mathrm{M}_{1}$ receptor in the astrocytes of an Alexander disease patient (top and middle panels, arrows). Arrowheads indicate Rosenthal fibers. GFAP marks astrocytes. DAPI labels nuclei. Scale bar, $10 \mu \mathrm{m}$. $\boldsymbol{B}$, Western blot shows significantly increased expression of $M_{1}$ receptors in the white matter of Alexander disease patients. The blot was reprobed with an antibody to GAPDH to illustrate equivalent protein loading. ${ }^{*} p<0.05$ (two-tailed Student's $t$ test).

A

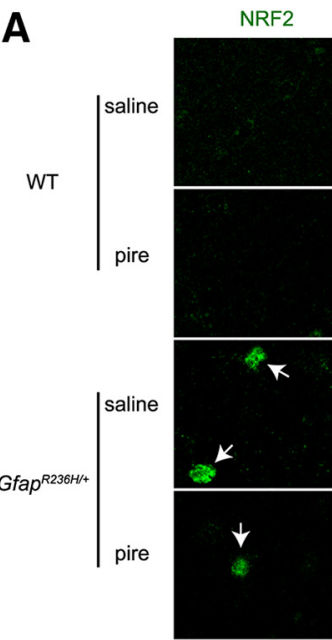
NRF2
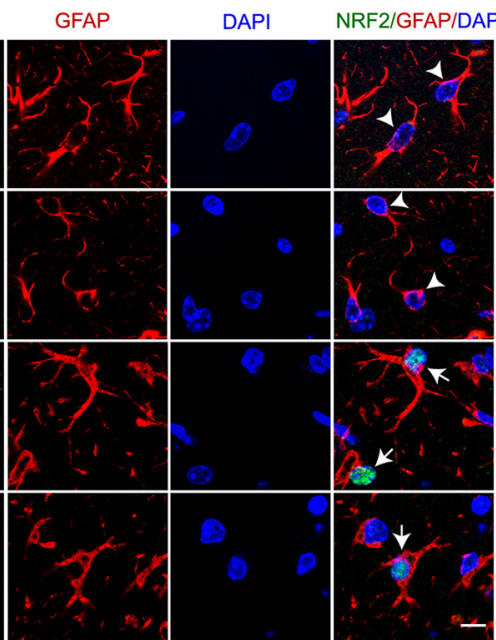

\section{B}

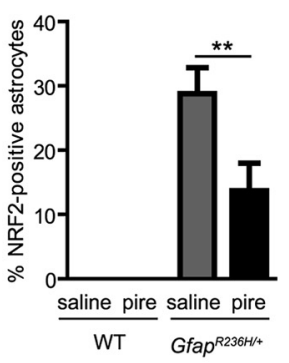

Figure 8. Pirenzepine treatment reduces NRF2 in Alexander disease model mice. $\boldsymbol{A}$, Double-label immunofluorescence reveals expression of NRF2 in astrocytes of Alexander disease model mice (bottom two rows), but not in age-matched wild-type control mice (top two rows). GFAP marks astrocytes. DAPI labels nuclei. Arrows indicate NRF2-positive astrocytes. Arrowheads indicate NRF2-negative astrocytes. Scale bar, $10 \mu \mathrm{m}$. B, Quantification in the hippocampal CA1 region shows a significant reduction of the percentage of NRF2-positive astrocytes in pirenzepine (pire)-treated Alexander disease model mice compared with saline-treated Alexander disease mice. ${ }^{* *} p<0.01$ (one-way ANOVA with Tukey's multiple-comparison test). Fifty astrocytes per animal and 5 or 6 animals per genotype/treatment were counted. Mice were 8 weeks old and were treated with $20 \mathrm{mg} / \mathrm{kg}$ pirenzepine or saline for $10 \mathrm{~d}$.

2011; Chen et al., 2012; Navarrete et al., 2012). Intracellular calcium in turn controls a variety of cellular processes, including exocytosis (Jourdain et al., 2007; Liu et al., 2011; Zorec et al., 2012; Kawamata et al., 2014). Because non-cell-autonomous neuronal death is a feature of astrocyte gliopathy in Alexander disease patients, in our Drosophila model of Alexander disease, and in other neurological disorders as well (Ilieva et al., 2009), inhibition of release of neurotoxic substances is an intriguing potential mechanism for the protective effect of mAChR blockade in our experiments. Alternatively, as G-proteincoupled receptors, muscarinic receptors regulate a number of other signaling cascades, including tyrosine and MAP kinase pathways (Felder, 1995; Nathanson, 2000; Wess et al., 2007), deregulation of which may lead to glial dysfunction and secondary neuronal toxicity. A recently published study suggests that targeting muscarinic cholinergic signaling may be a particularly attractive therapeutic approach in Alexander disease, a disorder with prominent white matter pathology in many patients. Deshmukh et al. (2013) demonstrated that benztropine, an FDA-approved anticholinergic compound currently in clinical use for Parkinson's disease, enhances remyelination in mouse models of experimental demyelination. In these studies, benztropine acted by antagonizing M1 and/or M3 receptors on oligodendrocyte precursor cells and promoting their differentiation. Thus, modulation of cholinergic signaling may have beneficial effects on multiple cell types affected directly or indirectly by mutant GFAP expression in astrocytes.

In conclusion, we have conducted an unbiased chemical screen using a Drosophila model of Alexander disease previously developed in our laboratory (Wang et al., 2011). We identified four compounds with prior approved use in humans, which showed dose-dependent efficacy in our model. We further performed genetic and additional pharmacological studies to validate muscarinic cholinergic signaling in the control of GFAP toxicity. Importantly, we confirmed key findings from our Drosophila model in Alexander disease model mice and postmortem patient tissue. Our results highlight the utility of Drosophila for

We chose to focus on muscarinic cholinergic signaling in our studies because astrocytes are known to express mAChRs (Guizzetti et al., 1996; Porter and McCarthy, 1997), and activation of these receptors controls a variety of important cellular processes. Of particular note, a number of studies have linked activation of $\mathrm{mAChRs}$ to increases in astrocyte calcium levels (Takata et al., unbiased chemical screens in drug development, even in the context of complex, aging-dependent phenotypes in the adult brain. In addition, we identify promising compounds and target pathways, including glial muscarinic cholinergic signaling, for a devastating and currently untreatable nervous system disorder. 


\section{References}

Agrawal T, Sadaf S, Hasan G (2013) Genetic RNAi screen for $\mathrm{IP}_{3} / \mathrm{Ca}^{2+}$ coupled GPCRs in Drosophila identifies the PdfR as a regulator of insect flight. PLoS Genet 9:e1003849. CrossRef Medline

Anisuzzaman AS, Uwada J, Masuoka T, Yoshiki H, Nishio M, Ikegaya Y, Takahashi N, Matsuki N, Fujibayashi Y, Yonekura Y, Momiyama T, Muramatsu I (2013) Novel contribution of cell surface and intracellular M1-muscarinic acetylcholine receptors to synaptic plasticity in hippocampus. J Neurochem 126:360-371. CrossRef Medline

Bonini NM, Fortini ME (2003) Human neurodegenerative disease modeling using Drosophila. Annu Rev Neurosci 26:627-656. CrossRef Medline

Brand AH, Perrimon N (1993) Targeted gene expression as a means of altering cell fates and generating dominant phenotypes. Development 118: 401-415. Medline

Brenner M, Johnson AB, Boespflug-Tanguy O, Rodriguez D, Goldman JE, Messing A (2001) Mutations in GFAP, encoding glial fibrillary acidic protein, are associated with Alexander disease. Nat Genet 27:117-120. CrossRef Medline

Chang S, Bray SM, Li Z, Zarnescu DC, He C, Jin P, Warren ST (2008) Identification of small molecules rescuing fragile $\mathrm{X}$ syndrome phenotypes in Drosophila. Nat Chem Biol 4:56-263. CrossRef Medline

Chen N, Sugihara H, Sharma J, Perea G, Petravicz J, Le C, Sur M (2012) Nucleus basalis-enabled stimulus-specific plasticity in the visual cortex is mediated by astrocytes. Proc Natl Acad Sci U S A 109:E2832-E2841. CrossRef Medline

Chong CR, Sullivan DJ Jr (2007) New uses for old drugs. Nature 448:645646. CrossRef Medline

Colodner KJ, Feany MB (2010) Glial fibrillary tangles and JAK/STATmediated glial and neuronal cell death in a Drosophila model of glial tauopathy. J Neurosci 30:16102-16113. CrossRef Medline

Deshmukh VA, Tardif V, Lyssiotis CA, Green CC, Kerman B, Kim HJ, Padmanabhan K, Swoboda JG, Ahmad I, Kondo T, Gage FH, Theofilopoulos AN, Lawson BR, Schultz PG, Lairson LL (2013) A regenerative approach to the treatment of multiple sclerosis. Nature 502:327-332. CrossRef Medline

Español AJ, Maddaleno MO, Lombardi MG, Cella M, Martínez Pulido P, Sales ME (2014) Treatment with LPS plus INF- $\gamma$ induces the expression and function of muscarinic acetylcholine receptors, modulating NIH3T3 cell proliferation: participation of NOS and COX. Br J Pharmacol 171: 5154-5167. CrossRef Medline

Feany MB, Bender WW (2000) A Drosophila model of Parkinson's disease. Nature 404:394-398. CrossRef Medline

Felder CC (1995) Muscarinic acetylcholine receptors: signal transduction through multiple effectors. FASEB J 9:619-625. Medline

Ganetzky B, Wu CF (1982) Drosophila mutants with opposing effects on nerve excitability: genetic and spatial interactions in repetitive firing. J Neurophysiol 47:501-514. Medline

Gasque G, Conway S, Huang J, Rao Y, Vosshall LB (2013) Small molecule drug screening in Drosophila identifies the 5HT2A receptor as a feeding modulation target. Sci Rep 3:srep02120. CrossRef Medline

Gomi H, Yokoyama T, Fujimoto K, Ikeda T, Katoh A, Itoh T, Itohara S (1995) Mice devoid of the glial fibrillary acidic protein develop normally and are susceptible to scrapie prions. Neuron 14:29-41. CrossRef Medline

Guizzetti M, Costa P, Peters J, Costa LG (1996) Acetylcholine as a mitogen: muscarinic receptor-mediated proliferation of rat astrocytes and human astrocytoma cells. Eur J Pharmacol 297:265-273. CrossRef Medline

Hagemann TL, Gaeta SA, Smith MA, Johnson DA, Johnson JA, Messing A (2005) Gene expression analysis in mice with elevated glial fibrillary acidic protein and Rosenthal fibers reveals a stress response followed by glial activation and neuronal dysfunction. Hum Mol Genet 14:24432458. CrossRef Medline

Hagemann TL, Connor JX, Messing A (2006) Alexander disease-associated glial fibrillary acidic protein mutations in mice induce Rosenthal fiber formation and a white matter stress response. J Neurosci 26:11162-11173. CrossRef Medline

Hagemann TL, Boelens WC, Wawrousek EF, Messing A (2009) Suppression of GFAP toxicity by alphaB-crystallin in mouse models of Alexander disease. Hum Mol Genet 18:1190-1199. CrossRef Medline

Ilieva H, Polymenidou M, Cleveland DW (2009) Non-cell autonomous toxicity in neurodegenerative disorders: ALS and beyond. J Cell Biol 187: 761-772. CrossRef Medline
Ishibashi M, Yamazaki Y, Miledi R, Sumikawa K (2014) Nicotinic and muscarinic agonists and acetylcholinesterase inhibitors stimulate a common pathway to enhance GluN2B-NMDAR responses. Proc Natl Acad Sci U S A 111:12538-12543. CrossRef Medline

Jackson GR, Wiedau-Pazos M, Sang TK, Wagle N, Brown CA, Massachi S, Geschwind DH (2002) Human wild-type tau interacts with wingless pathway components and produces neurofibrillary pathology in Drosophila. Neuron 34:509-519. CrossRef Medline

Jourdain P, Bergersen LH, Bhaukaurally K, Bezzi P, Santello M, Domercq M, Matute C, Tonello F, Gundersen V, Volterra A (2007) Glutamate exocytosis from astrocytes controls synaptic strength. Nat Neurosci 10:331339. CrossRef Medline

Kawamata H, Ng SK, Diaz N, Burstein S, Morel L, Osgood A, Sider B, Higashimori H, Haydon PG, Manfredi G, Yang Y (2014) Abnormal intracellular calcium signaling and SNARE-dependent exocytosis contributes to SOD1G93A astrocyte-mediated toxicity in amyotrophic lateral sclerosis. J Neurosci 34:2331-2348. CrossRef Medline

Li R, Johnson AB, Salomons G, Goldman JE, Naidu S, Quinlan R, Cree B, Ruyle SZ, Banwell B, D'Hooghe M, Siebert JR, Rolf CM, Cox H, Reddy A, Gutiérrez-Solana LG, Collins A, Weller RO, Messing A, van der Knaap MS, Brenner M (2005) Glial fibrillary acidic protein mutations in infantile, juvenile, and adult forms of Alexander disease. Ann Neurol 57:310 326. CrossRef Medline

Liu T, Sun L, Xiong Y, Shang S, Guo N, Teng S, Wang Y, Liu B, Wang C, Wang L, Zheng L, Zhang CX, Han W, Zhou Z (2011) Calcium triggers exocytosis from two types of organelles in a single astrocyte. J Neurosci 31: 10593-10601. CrossRef Medline

Markstein M, Dettorre S, Cho J, Neumüller RA, Craig-Müller S, Perrimon N (2014) Systematic screen of chemotherapeutics in Drosophila stem cell tumors. Proc Natl Acad Sci U S A 111:4530-4535. CrossRef Medline

Messing A, Head MW, Galles K, Galbreath EJ, Goldman JE, Brenner M (1998) Fatal encephalopathy with astrocyte inclusions in GFAP transgenic mice. Am J Pathol 152:391-398. Medline

Messing A, Brenner M, Feany MB, Nedergaard M, Goldman JE (2012) Alexander disease. J Neurosci 32:5017-5023. CrossRef Medline

Millar NS, Baylis HA, Reaper C, Bunting R, Mason WT, Sattelle DB (1995) Functional expression of a cloned Drosophila muscarinic acetylcholine receptor in a stable Drosophila cell line. J Exp Biol 198:1843-1850. Medline

Narushima M, Uchigashima M, Fukaya M, Matsui M, Manabe T, Hashimoto K, Watanabe M, Kano M (2007) Tonic enhancement of endocannabinoidmediated retrograde suppression of inhibition by cholinergic interneuron activity in the striatum. J Neurosci 27:496-506. CrossRef Medline

Nathanson NM (2000) A multiplicity of muscarinic mechanisms: enough signaling pathways to take your breath away. Proc Natl Acad Sci U S A 97:6245-6247. CrossRef Medline

Navarrete M, Perea G, Fernandez de Sevilla D, Gómez-Gonzalo M, Núñez A, Martín ED, Araque A (2012) Astrocytes mediate in vivo cholinergic-induced synaptic plasticity. PLoS Biol 10:e1001259. CrossRef Medline

Onai T, FitzGerald MG, Arakawa S, Gocayne JD, Urquhart DA, Hall LM, Fraser CM, McCombie WR, Venter JC (1989) Cloning, sequence analysis and chromosome localization of a Drosophila muscarinic acetylcholine receptor. FEBS Lett 255:219-225. CrossRef Medline

Pekny M, Levéen P, Pekna M, Eliasson C, Berthold CH, Westermark B, Betsholtz C (1995) Mice lacking glial fibrillary acidic protein display astrocytes devoid of intermediate filaments but develop and reproduce normally. EMBO J 14:1590-1598. Medline

Porter JT, McCarthy KD (1997) Astrocytic neurotransmitter receptors in situ and in vivo. Prog Neurobiol 51:439-455. CrossRef Medline

Shapiro RA, Wakimoto BT, Subers EM, Nathanson NM (1989) Characterization and functional expression in mammalian cells of genomic and cDNA clones encoding a Drosophila muscarinic acetylcholine receptor. Proc Natl Acad Sci U S A 86:9039-9043. CrossRef Medline

Sykiotis GP, Bohmann D (2008) Keap1/Nrf2 signaling regulates oxidative stress tolerance and lifespan in Drosophila. Dev Cell 14:76-85. CrossRef Medline

Takata N, Mishima T, Hisatsune C, Nagai T, Ebisui E, Mikoshiba K, Hirase $\mathrm{H}$ (2011) Astrocyte calcium signaling transforms cholinergic modulation to cortical plasticity in vivo. J Neurosci 31:18155-18165. CrossRef Medline

Uwada J, Yoshiki H, Masuoka T, Nishio M, Muramatsu I (2014) Intracellu- 
lar localization of the M1 muscarinic acetylcholine receptor through clathrin-dependent constitutive internalization is mediated by a C-terminal tryptophan-based motif. J Cell Sci 127:3131-3140. CrossRef Medline

van der Zee EA, Luiten PG (1999) Muscarinic acetylcholine receptors in the hippocampus, neocortex and amygdala: a review of immunocytochemical localization in relation to learning and memory. Prog Neurobiol 58: 409-471. CrossRef Medline

Wang L, Colodner KJ, Feany MB (2011) Protein misfolding and oxidative stress promote glial-mediated neurodegeneration in an Alexander disease model. J Neurosci 31:2868-2877. CrossRef Medline

Wess J, Eglen RM, Gautam D (2007) Muscarinic acetylcholine receptors: mutant mice provide new insights for drug development. Nat Rev Drug Discov 6:721-733. CrossRef Medline
Williams DW, Kondo S, Krzyzanowska A, Hiromi Y, Truman JW (2006) Local caspase activity directs engulfment of dendrites during pruning. Nat Neurosci 10:1234-1236. CrossRef Medline

Wittmann CW, Wszolek MF, Shulman JM, Salvaterra PM, Lewis J, Hutton M, Feany MB (2001) Tauopathy in Drosophila: neurodegeneration without neurofibrillary tangles. Science 293:711-714. CrossRef Medline

Yamasaki M, Matsui M, Watanabe M (2010) Preferential localization of muscarinic $\mathrm{M} 1$ receptor on dendritic shaft and spine of cortical pyramidal cells and its anatomical evidence for volume transmission. J Neurosci 30:4408-4418. CrossRef Medline

Zorec R, Araque A, Carmignoto G, Haydon PG, Verkhratsky A, Parpura V (2012) Astroglial excitability and gliotransmission: an appraisal of $\mathrm{Ca}^{2+}$ as a signalling route. ASN Neuro 4.pii:e000804. CrossRef Medline 